\title{
ESTRATÉGIAS DE APRENDIZAGEM DOS ESTUDANTES MOTIVADOS
}

\author{
Juliana Xavier de Castro ${ }^{1}$ \\ Gilberto José Miranda ${ }^{2}$ \\ Edvalda Araújo Leal ${ }^{3}$
}

\begin{abstract}
Resumo: Esta pesquisa tem como objetivo averiguar a frequência do uso de estratégias de aprendizagem, identificar a motivação para aprender e verificar a relação entre essas duas variáveis numa amostra de 480 alunos do curso de Ciências Contábeis de uma universidade pública brasileira. Os instrumentos de pesquisa utilizados foram a Escala de Estratégias de Aprendizagem de Boruchovitch e Santos (2004) e a Escala de Avaliação da Motivação para Aprender de Neves e Boruchovitch (2007). Para a apreciação dos resultados foi realizada a análise fatorial para agrupamento dos fatores relativos às duas escalas. Em seguida, foi aplicada a correlação linear para medir o índice de correlação entre os fatores gerados. Verificou-se que a relação entre a motivação intrínseca e o uso de estratégias de aprendizagem pelo aluno é significativa, ou seja, alunos intrinsicamente motivados estudam por vontade e prazer e, por isso, adotam procedimentos que melhoram os resultados do seu aprendizado. A relação entre a motivação extrínseca e a ausência de estratégias de aprendizagem também foi significativa, mostrando que alunos que estudam motivados por obrigações, recompensas e punições não utilizam estratégias de aprendizagem em seus estudos. Esses resultados sugerem que o uso de estratégias de aprendizagem pelos alunos é importante para o seu desempenho e é potencializado pela motivação intrínseca.
\end{abstract}

Palavras-chave: Estratégias de aprendizagem; Motivação intrínseca; Motivação extrínseca; Ciências Contábeis.

\footnotetext{
E-mail: xjuliana@hotmail.com -Universidade Federal de Uberlândia

2E-mail: gilbertojm@facic.ufu.br - Universidade Federal de Uberlândia

${ }^{3}$ E-mail: edvalda@facic.ufu.br - Universidade Federal de Uberlândia

- DOI: http://dx.doi.org/10.14392/asaa.2016090105

- Pesquisa financiada pela Fundação de Amparo à Pesquisa do Estado de Minas Gerais . Trabalho aprovado no V EnEPQ (2015).

- Artigo submetido em: 18/09/2015 Revisões requeridas em: 07/04/2016. Aceito em: 19/04/2016.
} 


\section{LEARNING STRATEGIES OF MOTIVATED STUDENTS}

Abstract: This study ascertain the frequency of use of learning strategies, identifies the motivation to learn and check the relationship between these two variables in a sample of 480 undergraduate students of accounting at a Brazilian public university. The research instruments used were the Learning Strategies Scale of Boruchovitch and Santos (2004) and the Learning Motivation Assessment Scale of Neves and Boruchovitch (2007). The data were submitted to factor analysis for grouping of the factors related to the two scales. Then linear correlation was applied to measure the correlation coefficient between the factors generated. We found that the relation between intrinsic motivation and the use of learning strategies by students was significant, i.e., intrinsically motivated students study willingly and for pleasure, so they adopt procedures that enhance their learning. The relation between extrinsic motivation and absence of learning strategies also was significant, showing that students who study due to obligation, rewards and punishments do not use learning strategies. These results suggest that the use of learning strategies by students is important for their performance and is enhanced by intrinsic motivation.

Keywords: Learning strategies; Intrinsic motivation; Extrinsic motivation; Accounting. 


\section{INTRODUÇÃO}

[ stratégias de aprendizagem são comportamentos desenvolvidos pelo aluno com a finalidade de - facilitar a recuperação da memória de conhecimentos já adquiridos e, assim, otimizar a qualidade do aprendizado. Dansereau (1985) e Nisbet e Schucksmith (1986) conceituam aprendizagem como uma forma por meio da qual o aluno escolhe sistematicamente suas atividades e procedimentos com a finalidade de adquirir, facilitar, armazenar e utilizar o conhecimento.

As estratégias de aprendizagem são classificadas em cognitivas e metacognitivas, como sugerido por Garner e Alexander (1989) e Dembo (1994). Esses autores definem estratégias cognitivas como comportamentos e pensamentos que influenciam o processo de aprendizagem, de forma que a informação seja recuperada mais eficientemente da memória sempre que necessário; e as estratégias metacognitivas, como procedimentos utilizados pelo estudante para planejar, monitorar e regular o próprio pensamento, visando sempre à realização de metas antes preestabelecidas.

Nesse sentido, fica evidente a utilização das estratégias de aprendizagem pelos alunos para abstrair e transformar as informações recebidas em conhecimentos. Entretanto, há outro fator relevante no processo de ensino e aprendizagem, qual seja, a motivação discente.

Quanto à motivação, há na literatura diversos conceitos, no entanto, existe um consenso entre os autores: a motivação, que é entendida como um processo ou um fator que faz uma pessoa agir e modificar seu curso em direção a um objetivo ou persistir na atividade (Bzuneck, 2009; Guimarães, 2009; Boruchovitch \& Bzuneck, 2010; Silva \& Mettrau, 2010).

No que se refere à motivação para aprender, para Graham e Weadiner (1996), embora existam várias explicações cada qual enfatizando uma abordagem específica, dois tipos de motivação são considerados chave para a compreensão do fenômeno: a motivação intrínseca e a motivação extrínseca.

A motivação intrínseca estabelece que o indivíduo realiza determinada tarefa como um fim em si mesmo, ou seja, quando existem interesse e prazer na execução, buscada por iniciativa própria. Em outras palavras, o aluno estuda por prazer.

Já a motivação extrínseca denota o cumprimento de determinada tarefa por um motivo externo a ela, como receber recompensas materiais ou sociais, evitar punições, ou sentir-se obrigado ou pressionado a fazer algo, mesmo que internamente. $\mathrm{O}$ aluno estuda para obter um emprego melhor, ou para agradar aos pais, por exemplo.

Diante desses conceitos, identifica-se o seguinte problema de pesquisa: qual a relação existente entre o uso das estratégias de aprendizagem e o tipo de motivação discente de alunos de Ciências Contábeis? Assim, o objetivo do estudo é verificar a relação existente entre o uso de estratégias de aprendizagem e o tipo de motivação discente de alunos de Ciências Contábeis.

Para realizar esta pesquisa, foi escolhido o curso de Ciências Contábeis de uma universidade pública brasileira. Considera-se oportuna essa escolha, uma vez que, segundo o Censo da Educação Superior do Brasil (CES) de 2013 (Instituto Nacional de Estudos e Pesquisas Educacionais Anísio Teixeira- INEP2013), esse curso é o quarto colocado no ranking dos dez maiores cursos de graduação do país em número de matrículas. Outro fator importante, segundo dados do Censo Nacional da Educação Superior, 
publicado em 2012, (Brasil, 2014), a nota média do curso de Ciências Contábeis no Exame Nacional de Desempenho dos Estudantes - ENADE (Brasil, 2012) é baixa, sendo de 34,5 pontos, numa escala de zero a cem. Espera-se que este estudo contribua com reflexões não apenas dos alunos, mas também da gestão acadêmica e do corpo docente, sobre como melhorar o processo ensino-aprendizagem dos alunos. O resultado do estudo realizado por Araújo, Lima, Oliveira e Miranda (2015), que investigou 574 docentes da área contábil, apontou que um dos principais problemas percebidos pelos professores de contabilidade, no exercício da docência, é a falta de motivação dos alunos. Tal fato reforça a relevância de se investigar a motivação dos discentes do curso de Ciências Contábeis e possibilidades de a instituição otimizar o processo de aprendizagem.

\section{REVISÃO DA LITERATURA}

\subsection{ESTRATÉGIAS DE APRENDIZAGEM}

Para Weinstein e Mayer (1985) e Weinstein, Aceee Jung (2011), estratégias de aprendizagem são ações mentais e comportamentais específicas adotadas pelo aluno durante o processo ensino-aprendizagem, que têm por objetivo facilitar e consolidar a construção do seu conhecimento. Pozo (1996) as define como comportamentos sequenciais ou atividades que se escolhem com o propósito de facilitar a aquisição, o armazenamento e a utilização da informação. De acordo com Silva e Sá (1997), as estratégias de aprendizagem têm um caráter consciente e intencional. Em nível mais específico, podem ser consideradas como qualquer ação adotada para a realização de uma tarefa. Os autores apontam, ainda, que a instrução em estratégias de aprendizagem possibilita aos estudantes ultrapassarem dificuldades pessoais e ambientais de forma a obter maior sucesso escolar.

As estratégias de aprendizagem vêm sendo consideradas pela literatura como importantes instrumentos de autorregulação do aluno, na medida em que contribuem para ajudá-lo a aprender a aprender e exercer mais controle sobre o seu próprio processo de aprendizagem (Pozo, 1996; Da Silva \& De Sá, 1997). De acordo com Zimmerman (1986), um estudante é autorregulado quando é capaz de ser ativo e responsável pelo seu próprio processo de aprendizagem, pois a autorregulação envolve metacognição, que é a capacidade de o aluno refletir sobre os seus processos cognitivos.

Os teóricos diferenciam as estratégias de aprendizagem em cognitivas e metacognitivas. Para Dembo (1994), enquanto as estratégias cognitivas são comportamentos e pensamentos que influenciam o processo de aprendizagem de maneira que a informação possa ser armazenada mais eficientemente, as estratégias metacognitivas referem-se a procedimentos que o indivíduo utiliza para planejar, monitorar e regular o seu próprio pensamento.

Dentre outras formas, o uso de estratégias cognitivas pelos alunos pode ser identificado por meio da seguinte questão:"Quando você está assistindo a uma aula, costuma anotar o que a professora está falando, mes $\neg$ mo quando ela não manda ou nada escreve na lousa?" (Neves \& Boruchovitch 2007).

Para investigação sobre o uso de estratégias metacognitivas, pode-se citar uma questão: "Você percebe quando está com dificuldade para aprender determinados assuntos ou matérias?" (Neves \& Boruchovitch 2007).

Perassinoto, Boruchovitch e Bzuneck (2013) avaliaram a frequência de uso de estratégias de aprendizagem e identificaram a motivação para aprender. Os autores exploraram a relação entre essas duas variáveis numa amostra de 314 alunos do Ensino Fundamental. Eles identificaram correlações positivas e significativas entre uso de estratégias de aprendizagem e motivação intrínseca. Quanto às respostas referentes à escala de estratégias de aprendizagem, o estudo evidenciou que os alunos do 
ensino fundamental, participantes da pesquisa, no conjunto, pareciam ser relativamente bons usuários de estratégias de aprendizagem. Entretanto, esses alunos reportaram menor frequência de uso das estratégias do tipo cognitivas, quando compaᄀradas às demais.

Os resultados das pesquisas sobre estratégias de aprendizagem mostraram que os alunos não apresentam um repertório diversificado de estratégias de aprendizagem e que não as utilizam com frequência e regularidade. Esses resultados revelam também que a intervenção para utilização de estratégias de aprendizagem tem sido bem-sucedida, de modo geral, pois é capaz de produzir melhoria em seu uso e no rendimento escolar dos alunos (Pressley \& Levin, 1983; Garner, Hare, Alexander, Hayes \& Winograd, 1984; Weinstein \& Mayer, 1985; Garner \& Alexander, 1989). No entanto, esses autores também enfatizam que apenas conhecer as estratégias não é suficiente para melhorar o rendimento escolar dos estudantes, sendo necessário que os alunos compreendam como utilizá-las.

Estratégias de aprendizagem podem ser ensinadas para alunos de baixo rendimento escolar com o intuito de melhorar o desempenho nas aulas, como: sublinhar pontos importantes de um texto, monitorar a compreensão da leitura, usar estratégias de memorização, fazer resumos, entre outras, pois elas são capazes de melhorar de forma significativa o rendimento do aluno (Boruchovitch \& Santos, 2006). Entretanto, conforme mencionado por Hattie, Biggs e Purdie (1996), a intervenção em estratégias de aprendizagem somente será eficaz para desenvolver a capacidade do aluno de aprender a aprender se a elas forem associadas a estratégias de apoio afetivo, destinadas a modificar variáveis psicológicas, tais como, ansiedade, autoeficácia, autoconceito, atribuição de causalidade, muitas vezes, incompatíveis ao uso apropriado das estratégias.

Depreende-se, portanto, que, além de conhecer e saber quando e como utilizar as estratégias de aprendizagem, é importante que o aluno tenha motivação para pô-las em prática, pois, dessa maneira, o uso de estratégias de aprendizagem poderá ser otimizado.

\subsection{MOTIVAÇÃO INTRÍNSECA E EXTRÍNSECA}

Cardoso e Bzuneck (2004) afirmam que a motivação é entendida como um processo ou um fator que faz uma pessoa agir, modificar seu curso em direção a um objetivo ou persistir na atividade. As investigações sobre a motivação para a aprendizagem e os fatores relacionados ao desempenho escolar têm sido realizadas por educadores e psicólogos. As teorias sociais cognitivas da motivação para a aprendizagem têm demonstrado a existência de pelo menos duas formas principais de motivação: a intrínseca e a extrínseca (Mandelink \& Harackiewicz, 1984; Csikszentmihalyi \& Nakamura, 1989; Harackiewicks \& Elliot, 1993; Amabile, Hill, Hennessey \& Tighe, 1994; Fortier, Vallerand \& Guay, 1995).

Entre os teóricos, não há discordância sobre as conceituações básicas de motivação intrínseca e extrínseca. A motivação intrínseca é aquela que se manifesta no indivíduo quando ele executa determinada tarefa por interesse e prazer; nesse caso, ela é buscada por iniciativa própria, isto é, o incentivo já reside na própria execução da atividade, chamada, então, de autotélica (Guimarães, 2009).

Ao contrário da motivação intrínseca, a extrínseca denota o cumprimento de determinada tarefa por um motivo externo a ela: receber recompensas materiais ou sociais, evitar punições ou sentir-se obrigado ou pressionado, mesmo que internamente, a fazer algo. Um aluno é intrinsecamente motivado quando se mantém na tarefa por prazer. Por outro lado, pode-se dizer que um aluno é extrinsecamente motivado quando o seu objetivo em realizar uma dada tarefa é externo à própria tarefa (Guimarães, 2009). 
Na história dos estudos sobre motivação intrínseca e extrínseca no contexto escolar, identificam-se duas tradições. Na primeira delas, o foco tem sido a simples dicotomia intrínseca-extrínseca, com estudos principais como os de Harter (1981), Mitchell Jr. (1992) e Amabile et al (1994). No Brasil, destacam-se, nessa linha, as pesquisas de Siqueira e Wechsler (2006), Boruchovitch (2006), Martinelli e Genari (2009), dentre outros.

A segunda tradição tem se reportado à Teoria da Autodeterminação, conforme apontam Deci \& Ryan (1985) e Ryan \& Deci (2000), segundo a qual a motivação extrínseca se subdivide em quatro níveis de regulação, por meio de um continuum de internalização que vai desde uma forma puramente externa até uma regulação integrada, próxima à motivação intrínseca. Os autores também defendem que a motivação intrínseca e as formas autorreguladas da motivação extrínseca dependem da satisfação das três necessidades básicas: competência, autonomia e relacionamento.

Sabe-se que a motivação para aprender é considerada uma variável-chave para a autorregulação da aprendizagem, sendo, portanto, muitas vezes, medida como uma subescala de instrumentos relativos à autorregulação da aprendizagem (Shil, 2005).

Investigações sobre mensuração da motivação para aprender dos estudantes, com diferentes metodologias, têm revelado resultados importantes para a psicologia escolar e educacional. Entre os instrumentos disponíveis, destaca-se: a Escala de Motivação Intrínseca, desenvolvida por Harter (1981).

Harter (1981) desenvolveu uma pesquisa com três mil estudantes, cujo objetivo foi desenvolver um instrumento para conhecer a motivação da criança em sala de aula. Para a construção do instrumento, o autor definiu cinco dimensões bipolares para caracterizar a motivação intrínseca e a motivação extrínseca, a saber: preferência maior por assuntos desafiadores ou fáceis; preferência por trabalhar de forma independente ou por depender de ajuda externa; a aprendizagem por curiosidade ou pelo desejo de agradar ao professor; o estudo pela própria satisfação ou para agradar ao professor e obter boas avaliações; e o uso de critérios internos ou externos para determinar o sucesso e o fracasso escolar. Os resultados indicaram que a Escala de Motivação Intrínseca de Harter (1981), com a consistência interna variando de 0,68 a 0,84, é uma medida fidedigna e válida para avaliar a motivação intrínseca e extrínseca de crianças.

Lepper, Corpus e Lyengar (2005) modificaram a versão original do instrumento de Harter (1981) com o intuito de construir medidas independentes da motivação intrínseca e extrínseca. As duas escalas do tipo Likert desenvolvidas por esses autores foram aplicadas a 797 estudantes de $3^{\mathrm{a}}$ a $8^{\mathrm{a}}$ série de escolas públicas americanas. Essas escalas apresentaram boas propriedades psicométricas, com a consistência interna variando de 0,78, para a motivação extrínseca, a 0,90, para a motivação intrínseca. A escala de motivação intrínseca apontou uma possível estrutura unifatorial desse constructo, visto que os itens relativos ao desafio, à curiosidade e ao trabalho independente carregaram todos no mesmo fator. Já na escala de motivação extrínseca, emergiram três fatores: facilidade da tarefa, agradar ao professor e dependência do professor.

$\mathrm{Na}$ área de negócios, outras pesquisas também buscaram identificar fatores que influenciam no desempenho do aluno. No estudo elaborado por Mamede, Marques, Rogers e Miranda (2015), sobre variáveis comportamentais, foi verificado que a crença do controle por pessoas poderosas está positivamente associada ao desempenho discente, e que a crença no acaso, sorte ou destino está negativamente relacionada ao rendimento do aluno. Já as variáveis autoeficácia, otimismo, lócus de controle interno, alta e baixa estima, conforme a pesquisa, não estão relacionadas ao desempenho dos alunos de Ciências Contábeis, objeto do estudo. 
Leal, Miranda e Carmo (2013) avaliaram a motivação dos alunos de Ciências Contábeis de uma universidade pública brasileira à luz da Teoria da Autodeterminação. Os resultados encontrados identificaram a existência de uma motivação bem diversificada para a aprendizagem entre os universitários estudados. Foram encontrados alunos preocupados em aprofundar o nível de conhecimentos ou em atingir uma fundamentação adequada para o desempenho de sua futura atuação, bem como alunos que estão preocupados apenas com a obtenção do diploma ou interessados em comparecer às aulas para garantir frequência.

Considerando a importância da motivação no processo de ensino e aprendizagem, a presente pesquisa investiga se há relação entre o uso de estratégias de aprendizagem e a motivação para aprender (intrínseca e extrínseca) entre os alunos do ensino superior do curso de Ciências Contábeis.

\section{PERCURSO METODOLÓGICO}

\subsection{CLASSIFICAÇÃO DA PESQUISA}

Quanto à abordagem, esta pesquisa configura-se como quantitativa. Para Gonçalves e Meirelles (2004), nas pesquisas quantitativas, os dados são representados por meio de métricas quantitativas, apresentando como elemento de apoio central a linguagem matemática como forma de expressão e tratamento. Em relação aos objetivos, a pesquisa é classificada como descritiva, pois, em conformidade com o que leciona Triviños (2007), pretende descrever os fatos e fenômenos de determinada realidade.

\subsection{COLETA DE DADOS}

Quanto ao procedimento de coleta de dados, recorreu-se ao levantamento (survey), com a aplicação de um questionário aos alunos do curso de Ciências Contábeis de uma universidade pública brasileira.

Para a coleta de dados, foi solicitada a autorização ao coordenador de curso, sendo, posteriormente, solicitado aos professores do curso que aplicassem o questionário em sala de aula aos alunos matriculados do primeiro ao décimo período. Os dados foram coletados no mês de maio de 2015.

Antes da aplicação do questionário, foi realizado um pré-teste com 08 alunos do curso de mestrado em Ciências Contábeis da instituição objeto desta pesquisa. Naquela oportunidade, os alunos sugeriram melhorias para a compreensibilidade do instrumento de pesquisa.

O questionário foi organizado em três blocos. No primeiro, são levantadas informações para caracterização dos respondentes. No segundo bloco, são apresentadas trinta e quatro assertivas acerca da motivação para aprender. Por último, no terceiro bloco, apresentam-se vinte assertivas sobre o uso das estratégias de aprendizagem.

Para cada assertiva, os respondentes atribuíram uma nota de zero a dez, o que indicava o grau de concordância, sendo: 0 (zero) - “Nunca”; 10 (dez), o maior grau de concordância, "Sempre”. Nas posições intermediárias de 1 a 9, estavam os graus de concordância intermediária.

As questões referentes ao uso de estratégias de aprendizagem foram adaptadas da Escala de Estratégias de Aprendizagem do Ensino Fundamental - EAEF de Boruchovitch e Santos (2004). Eram 05 (cinco) questões relativas às estratégias cognitivas, 07 (sete) questões relacionadas às estratégias metacognitivas e 08 (oito) questões referentes à ausência de estratégias metacognitivas disfuncionais.

Para avaliar os construtos motivacionais, foi adaptada a escala de avaliação da motivação para aprender de alunos do ensino fundamental de Neves e Boruchovitch (2007), com 34 itens, sendo 17 
(dezessete) referentes à motivação intrínseca e 17 (dezessete) relacionados à motivação extrínseca.

\subsection{COMPOSIÇÃO DA AMOSTRA}

A população deste estudo refere-se a 820 alunos matriculados no curso de Ciências Contábeis de uma instituição pública brasileira. A instituição oferece o curso de Ciências Contábeis em dois turnos: integral e noturno, sendo o quadro docente composto por 30 professores (efetivos e substitutos). A amostra do estudo corresponde a 480 (quatrocentos e oitenta) alunos do curso que responderam à pesquisa, o que representa $58,5 \%$ da população.

\subsection{ANÁLISE DOS DADOS}

Para a análise dos dados, foram utilizados dois testes estatísticos: primeiramente, a análise fatorial exploratória e, posteriormente, a correlação linear. A análise fatorial foi aplicada com o objetivo de sumarizar os dados por meio da combinação linear (fatores) (Fávero, Belfiore, Silva \& Chan, 2009). Esse teste foi aplicado para agrupar as variáveis associadas entre si, relacionadas à motivação, e também para as estratégias de ensino.

Para a realização da análise fatorial exploratória, segundo Fávero et al. (2009), a amostra deve ser composta por um número de observações de, no mínimo, 5 vezes maior que o número de variáveis investigadas. Nesta pesquisa, a primeira parte do instrumento possuía 34 variáveis relacionadas à motivação para aprender. Como participaram da pesquisa 480 alunos, têm-se 14,12 observações para cada variável. O referido autor estabelece ainda que, para realização da análise fatorial, deve-se avaliar o KMO (Kaiser-Meyer-Olkin), pois “[...] valores de KMO próximos de zero indicam que a análise fatorial pode não ser adequada, já que explicam a existência de uma fraca correlação entre as variáveis". Neste estudo, o KMO se mostrou adequado à utilização da análise fatorial, pois foi de 0,906. A segunda parte do instrumento continha 20 variáveis relacionadas às estratégias de aprendizagem. Considerando-se que participaram da pesquisa 480 alunos, são 24 observações para cada variável. O KMO de 0,796 também se mostrou adequado à utilização da análise fatorial (FÁVERO et al., 2009).

Para a análise das correlações entre as estratégias de aprendizagem e a motivação para aprender, foi aplicado o coeficiente de correlação de Spearman, devido à constatada ausência de distribuição normal das variáveis pesquisadas.

\section{DESCRIÇÃO E RESULTADOS}

\subsection{DESCRIÇÃO DOS DADOS}

A Tabela 1 apresenta a caracterização dos respondentes investigados na primeira etapa do instrumento de pesquisa.

Tabela 1: Caracterização dos respondentes

\begin{tabular}{|c|c|c|c|}
\hline \multicolumn{2}{|c|}{ Gênero } & \multicolumn{2}{c|}{ Experiência Profissional } \\
\hline Masculino & $39,0 \%$ & $\operatorname{Sim}$ & $65,2 \%$ \\
\hline Feminino & $59,8 \%$ & Não & $34,6 \%$ \\
\hline Não respondeu & $1,3 \%$ & Não respondeu & $2,0 \%$ \\
\hline Total & $100 \%$ & Total & $100 \%$ \\
\hline \multicolumn{2}{|c|}{ Turno } & \multicolumn{2}{c|}{$\begin{array}{c}\text { Participação em Atividades Acadêmicas } \\
\text { (PET, IC, Monitoria, Empresa Jr., etc.) }\end{array}$} \\
\hline
\end{tabular}




\begin{tabular}{|c|c|c|c|}
\hline Integral & $53,1 \%$ & Sim & $8,8 \%$ \\
\hline Noturno & $45,4 \%$ & Não & $90.8 \%$ \\
\hline Não respondeu & $1,5 \%$ & Não respondeu & $4,0 \%$ \\
\hline Total & $100 \%$ & Total & $100 \%$ \\
\hline \multicolumn{4}{|c|}{ Período matriculado } \\
\hline $1^{\circ}$ período & $12,1 \%$ & $6^{\circ}$ período & $9,8 \%$ \\
\hline $2^{\circ}$ período & $8,5 \%$ & $7^{\circ}$ período & $6,5 \%$ \\
\hline $3^{\circ}$ período & $12,3 \%$ & $8^{\circ}$ período & $9,6 \%$ \\
\hline $4^{\circ}$ período & $11,0 \%$ & $9^{\circ}$ período & $9,2 \%$ \\
\hline $5^{\circ}$ período & $10,0 \%$ & $10^{\circ}$ período & $11,0 \%$ \\
\hline \multicolumn{4}{|c|}{ Idade } \\
\hline \multicolumn{2}{|l|}{ Menos de 17 anos } & & \\
\hline \multicolumn{2}{|l|}{ De 17 a 20 anos } & & \\
\hline \multicolumn{2}{|l|}{ De 20 a 25 anos } & & \\
\hline \multicolumn{2}{|l|}{ Mais de 25 anos } & & \\
\hline \multicolumn{2}{|l|}{ Não respondeu } & & \\
\hline \multicolumn{2}{|l|}{ Total } & & \\
\hline
\end{tabular}

Fonte: Dados da Pesquisa.

Verifica-se que, do total de respondentes, 59,8\% são do sexo feminino, 65,2\% já têm experiência profissional na área contábil, 53,1\% estudam no turno integral e apenas $8,8 \%$ dos alunos participam ou já participaram de atividades acadêmicas extraclasse (monitoria, iniciação científica e programa de ensino tutorial). Ademais, 43,1\% dos respondentes têm de 20 a 25 anos de idade.

\subsection{RESULTADO DA ANÁLISE FATORIAL - MOTIVAÇÃO PARA APRENDER}

A Tabela 2 apresenta os cinco fatores apurados na análise fatorial da variável motivação para aprender. Os cinco fatores identificados explicam $52,61 \%$ da variação total dos dados. Todos os itens obtiveram cargas fatoriais aceitáveis, acima de 0,40 , o que está em conformidade com o que recomenda Hair et al. (2005).

Tabela 2: Análise Fatorial (Rotação Varimax) - Motivação para Aprender

\begin{tabular}{|c|c|c|c|c|c|c|}
\hline Itens & $\mathrm{Tp}$ & $\mathrm{F} 1$ & $\mathrm{~F} 2$ & $\mathrm{~F} 3$ & $\mathrm{~F} 4$ & F5 \\
\hline 1. Eu estudo porque estudar é importante para mim & Ml & 483 & & & & \\
\hline 3. Eu tenho vontade de conhecer e aprender assuntos novos & Ml & 683 & & & & \\
\hline 5. Eu gosto de estudar assuntos desafiantes & Ml & 619 & & & & \\
\hline 7. Eu gosto de estudar assuntos difíceis & MI & ,643 & & & & \\
\hline 11.Eu estudo mesmo sem a influência de outras pessoas & Ml & "486 & & & & \\
\hline 15.Eu estudo porque estudar me dá prazer e alegria & $\mathrm{Ml}$ & ,635 & & & & \\
\hline 17.Eu fico tentando resolver uma tarefa, mesmo quando ela é difícil para mim & MI & ,516 & & & & \\
\hline $\begin{array}{l}\text { 19.Eu prefiro aprender, na escola, assuntos que aumentem minhas habilidades ou } \\
\text { meus conhecimentos }\end{array}$ & MI &, 501 & & & & \\
\hline 23.Eu estudo porque gosto de ganhar novos conhecimentos & MI & ,717 & & & & \\
\hline 25.Eu gosto de estudar & MI & ,676 & & & & \\
\hline $\begin{array}{l}\text { 27.Eu procuro saber mais sobre os assuntos que gosto, mesmo sem meus professores } \\
\text { pedirem }\end{array}$ & MI & ,624 & & & & \\
\hline 29.Eu gosto de ir para a escola porque aprendo assuntos interessantes lá & Ml & 648 & & & & \\
\hline 31.Eu estudo porque quero aprender cada vez mais & MI & ,755 & & & & \\
\hline 33.Eu fico interessado (a) quando os professores começam lições novas & Ml & ,688 & & & & \\
\hline 2. Eu estudo por medo de as pessoas de minha convivência brigarem comigo & ME & &, 556 & & & \\
\hline 10. Eu estudo porque meus professores acham importante & ME & & ,646 & & & \\
\hline 12.Eu estudo porque fico preocupado (a) que as pessoas não me achem inteligente & ME & & ,672 & & & \\
\hline 14.Eu estudo por medo de punições por mal desempenho & ME & & ,536 & & & \\
\hline
\end{tabular}




\begin{tabular}{|c|c|c|c|c|c|c|}
\hline $\begin{array}{l}\text { 18.Eu estudo para que as pessoas da minha convivência me retribuam com coisas que } \\
\qquad \text { eu gosto }\end{array}$ & ME & & ,702 & & & \\
\hline 20.Eu só estudo para agradar meus professores & ME & & ,757 & & & \\
\hline $\begin{array}{l}\text { 26.Eu só faço meus deveres de casa porque as pessoas de minha convivência acham } \\
\text { importante }\end{array}$ & ME & & ,797 & & & \\
\hline 30.Eu só estudo porque as pessoas de minha convivência me mandam & ME & & ,747 & & & \\
\hline 4. Eu faço os deveres de casa por obrigação & ME & & & ,470 & & \\
\hline 16.Eu só estudo para não me sair mal na escola & ME & & & ,605 & & \\
\hline 22. Eu prefiro estudar assuntos fáceis & ME & & &, 692 & & \\
\hline 24.Eu estudo apenas aquilo que os professores avisam que vai cair na prova & ME & & &, 598 & & \\
\hline 28.Eu só estudo porque quero tirar notas altas & ME & & &, 608 & & \\
\hline 34. Eu desisto de fazer uma tarefa quando encontro dificuldade & ME & & &, 590 & & \\
\hline $\begin{array}{l}\text { 9. Eu me esforço bastante nos trabalhos de casa, mesmo sabendo que não vão valer } \\
\text { como nota }\end{array}$ & MI & & & & ,715 & \\
\hline $\begin{array}{l}\text { 13.Eu me esforço bastante nos trabalhos, em sala de aula, mesmo sabendo que não } \\
\text { vai valer como nota }\end{array}$ & MI & & & & ,752 & \\
\hline 21.Eu faço minhas lições de casa, mesmo sem a influência de outras pessoas & MI & & & & 674 & \\
\hline 6. Eu estudo para ter um bom emprego no futuro & ME & & & & & ,695 \\
\hline 8. Eu estudo porque serei recompensado na empresa ou por meus pais & ME & & & & & ,654 \\
\hline 32.Eu estudo por obrigação & ME & & & & & \\
\hline Autovalores (eigenvalue) & & 8,750 & 4,434 & 2,181 & 1,513 & 1,187 \\
\hline \% Variância explicada & & 18,470 & 12,620 & 8,640 & 8,392 & 4,490 \\
\hline \% Variância Acumulada & & 18,470 & 31,090 & 39,730 & 48,122 & 52,612 \\
\hline Alfa de Cronbach & & 0,899 & 0,841 & 0,735 & 0,804 & 0,332 \\
\hline
\end{tabular}

Fonte: Dados da Pesquisa

Para medir a confiabilidade do questionário, foi aplicado o coeficiente de consistência interna Alpha de Cronbach, que mede a correlação entre respostas em um questionário, por meio da análise do perfil das respostas dadas pelos respondentes. Dos cinco fatores gerados, apenas o quinto apresentou coeficiente abaixo de 0.70 , resultado recomendado pela literatura (Hair, Black, Babin, Anderson \& Tatham, 2005). O fator 5 teve baixa consistência interna em virtude de um número restrito de itens que se agruparam em torno desse fator, o que impossibilita análises mais aprofundadas sobre ele.

Pode-se notar que os itens relativos à motivação intrínseca se dividiram em dois fatores, quais sejam, os fatores 1 e 4 . O fator 1 foi denominado "Motivação Intrínseca - Vontade e prazer" porque agrupou variáveis que denotam motivações intrínsecas positivas, visto que os alunos demonstram satisfação ao estudar, como, por exemplo: eu estudo porque estudar é importante para mim, eu tenho vontade de conhecer e aprender assuntos novos, eu gosto de ir para a escola porque aprendo assuntos interessantes, e lá, eu fico interessado (a) quando os professores começam lições novas.

O fator 4, que foi chamado de "Motivação intrínseca - esforço próprio", também agrupou variáveis de conotação positiva, as quais demonstram que o aluno realiza suas tarefas como um fim em si mesmo, ou seja, com interesse e por iniciativa própria, tais como: eu me esforço bastante nos trabalhos de casa, mesmo sabendo que não vão valer como nota, eu faço minhas lições de casa, mesmo sem a influência de outras pessoas e eu me esforço bastante nos trabalhos, em sala de aula, mesmo sabendo que não vai valer como nota.

Importante ressaltar que o estudo realizado por Leal, Miranda e Carmo (2013), que também analisou a motivação dos alunos do curso de Ciências Contábeis, identificou que, em sua maioria, os alunos apresentaram-se intrinsecamente motivados, ou seja, esses alunos têm interesse e prazer na realização das tarefas acadêmicas, corroborando com as pesquisas de Boruchovitch (2008) e Perassinoto, Boruchovitch e Bzuneck (2013), realizadas em outras áreas do conhecimento. 
A motivação externa se dividiu em três fatores: o fator 2, denominado "Motivação extrínseca por punição"; o fator 3, chamado de "Motivação extrínseca - apenas obrigação"; e o fator 5, "Motivação extrínseca - por recompensa". Todos eles foram compostos por variáveis que mostram que os alunos cumprem suas tarefas por motivos externos a sua vontade, como receber recompensas materiais ou sociais, evitar punições, ou apenas por sentirem-se obrigados ou pressionados a fazer algo. Alguns dos exemplos são: eu estudo porque fico preocupado (a) que as pessoas não me achem inteligente, eu estudo apenas aquilo que os professores avisam que vai cair na prova e eu estudo porque serei recompensado na empresa ou por meus pais.

Neves e Boruchovitch (2004) e Paiva e Boruchovitch (2010) identificaram, na avaliação dos construtos motivacionais, a superioridade da média grupal na motivação intrínseca, em comparação com a extrínseca. Os autores abordaram que, embora haja um predomínio da motivação intrínseca no início da escolarização for-mal, ela tende a decair à medida que os alunos avançam nas séries escolares. Perassinoto, Boruchovitch e Bzuneck (2013) também perceberam, na amostra investigada, a tendência dos participantes à motivação intrínseca, embora a motivação extrínseca tenha sido considerável.

\subsection{RESULTADOS DA ANÁLISE FATORIAL - ESTRATÉGIAS DE APRENDIZAGEM}

A Tabela 3 apresenta os fatores identificados na Análise Fatorial (rotação varimax) da segunda parte do instrumento, relativa às estratégias de aprendizagem.

O coeficiente de consistência interna Alpha de Cronbach ficou acima de 0.70 em todos os fatores, conforme recomenda a literatura (HAIR et al. 2005). Verificou-se a redução dos 20 itens para 3 fatores, os quais explicam $41,27 \%$ da variação total dos dados. Todos os itens obtiveram cargas fatoriais aceitáveis, acima de 0,40, conforme orienta Hair et al. (2005).

Tabela 3: Análise Fatorial (Rotação Varimax) - Estratégias de Aprendizagem

\begin{tabular}{|c|c|c|c|c|}
\hline Itens & $\mathrm{Tp}$ & $\mathrm{F} 1$ & $\mathrm{~F} 2$ & F3 \\
\hline 13. Você costuma estudar ou fazer o dever de casa na "última hora"? & AUS & ,737 & & \\
\hline 15. Você costuma ficar pensando em outra coisa quando o professor está dando explicações? & AUS & ,686 & & \\
\hline 18. Você costuma se distrair ou pensar em outra coisa quando está lendo ou fazendo tarefas de casa? & AUS & ,649 & & \\
\hline 19. Você costuma "se esquecer" de fazer as tarefas de casa? & AUS & 674 & & \\
\hline 20. Você se sente cansado quando lê, estuda ou faz o dever de casa? & AUS & ,697 & & \\
\hline 2. Você percebe quando está com dificuldade para aprender determinados assuntos ou matérias? & META & & ,656 & \\
\hline 4. Quando você estuda, você percebe se não está conseguindo aprender? & META & & ,622 & \\
\hline 8. Quando você estuda, você consegue perceber o quanto está aprendendo? & META & & ,638 & \\
\hline 9. Você costuma pedir ajuda ao colega ou a alguém de sua casa, quando não entende alguma matéria? & META & & ,451 & \\
\hline 11. Você percebe quando não entende o que está lendo? & META & & ,788 & \\
\hline 12. Quando você percebe que não entendeu o que leu, você costuma parar e ler novamente? & META & &, 588 & \\
\hline 3. Você resume os textos que o professor pede para estudar? & COGN & & & ,636 \\
\hline $\begin{array}{l}\text { 5. Quando você lê um texto, procura escrever com suas palavras o que entendeu da leitura, para estudar } \\
\text { depois? }\end{array}$ & COGN & & & ,772 \\
\hline 6. Você cria perguntas e respostas sobre o assunto que está estudando? & COGN & & & ,746 \\
\hline 7. Você costuma fazer um esquema, usando as ideias principais do texto? & COGN & & &, 747 \\
\hline 10. Você costuma ler outros textos e livros sobre o assunto que o professor explicou em aula? & COGN & & &, 406 \\
\hline Autovalores (eigenvalue) & & 4,083 & 2,880 & 2,124 \\
\hline \% Variância explicada & & 15,811 & 12,843 & 12,632 \\
\hline \% Variância Acumulada & & 15,811 & 28,654 & 41,286 \\
\hline Alfa de Cronbach & & 0,795 & 0,669 & 0,766 \\
\hline
\end{tabular}


O fator 1 foi denominado "Ausência de estratégias" porque agrupou variáveis que denotam que os alunos não fazem uso de estratégias de aprendizagem, como por exemplo, estudar ou fazer o dever de casa na "última hora", ficar pensando em outra coisa quando o professor está dando explicações, "se esquecer" de fazer as tarefas de casa, etc.

O fator 2 "Estratégias metacognitivas" foi composto por variáveis que simbolizam procedimentos utilizados pelos alunos para planejar e controlar seus pensamentos, tais como: quando o aluno percebe que não está conseguindo aprender nem entender o que está lendo ou mesmo quando pede ajuda dos colegas ou alguém de casa ao notar dificuldade de compreender o que foi estudado.

O fator 3 "Estratégias cognitivas" agrupou variáveis que denotam procedimentos que o aluno utiliza para planejar, monitorar e regular o seu próprio pensamento, como: resumir os textos que o professor pede para estudar, criar perguntas e respostas para o que foi estudado, reescrever o que foi lido com suas próprias palavras, dentre outros.

Perassinoto, Boruchovitch e Bzuneck (2013, p.352) reportaram que "resultados provenientes de pes $\neg$ quisas sobre estratégias de aprendizagem revelam que os alunos apresentam um repertório não muito diversifica do de estratégias de aprendizagem e que não as utilizam com frequência e regularidade". Os autores verificaram, em linhas gerais, na pesquisa realizada, que os participantes indicam ser relativamente bons usuários de estratégias de aprendizagem, sobreᄀtudo, das metacognitivas; já o uso de estratégias cognitivas entre os participantes foi mais baixo do que o uso das metacognitivas.

\subsection{RESULTADO DA ANÁLISE DA CORRELAÇÃO}

A Tabela 4 apresenta o resultado da correlação linear de Spearman entre estratégias de aprendizagem e os tipos de motivação.

Tabela 4: Correlação Linear de Spearman entre estratégias de aprendizagem e os tipos de motivação.

\begin{tabular}{|c|c|c|c|c|c|c|}
\hline \multicolumn{2}{|c|}{ Estratégias / Tipo de Motivação } & $\begin{array}{l}\text { F1-Motivação } \\
\text { intrínseca }\end{array}$ & $\begin{array}{l}\text { F2-Motivação } \\
\text { extrínseca }\end{array}$ & $\begin{array}{l}\text { F3-Motivação } \\
\text { extrínseca }\end{array}$ & $\begin{array}{c}\text { F4-Motivação } \\
\text { intrínseca (esforço }\end{array}$ & $\begin{array}{c}\text { F4-Motivação } \\
\text { intrínseca (esforço }\end{array}$ \\
\hline \multirow{3}{*}{$\begin{array}{l}\text { F1 - Ausência de } \\
\text { estratégias }\end{array}$} & Coeficiente &,$- 321(* *)$ &,- 013 &, $382(* *)$ &,$- 337(* *)$ & 027 \\
\hline & Sig. (2-tailed) &, 000 & ,798 & , 000 & ,000 & ,588 \\
\hline & $\mathrm{N}$ & 411 & 411 & 411 & 411 & 411 \\
\hline \multirow{3}{*}{$\begin{array}{l}\text { F2 - Estratégias } \\
\text { metacognitivas }\end{array}$} & Coeficiente &, $254\left(^{* *}\right)$ &,$- 307(* *)$ &, $137(* *)$ &, $120(*)$ & ,096 \\
\hline & Sig. (2-tailed) &, 000 & ,000 & ,006 & 015 & 051 \\
\hline & $\mathrm{N}$ & 411 & 411 & 411 & 411 & 411 \\
\hline \multirow{3}{*}{$\begin{array}{l}\text { F3 - Estratégias } \\
\text { cognitivas }\end{array}$} & Coeficiente &, $185\left(^{(* *)}\right.$ &, $148(* *)$ & 027 &, $224\left(^{* *}\right)$ &,- 004 \\
\hline & Sig. (2-tailed) &, 000 & ,003 &, 584 & 000 & ,930 \\
\hline & $\mathrm{N}$ & 411 & 411 & 411 & 411 & 411 \\
\hline
\end{tabular}

Nota-se a correlação negativa (ao nível de significância de 1\%) entre "Ausência de Estratégias" e os dois fatores relativos à Motivação Intrínseca (F1 e F4). Isso significa que, quanto menor a motivação intrínseca, maior a ausência de estratégias de aprendizagem. Esses achados corroboram resultados de estudos anteriores, os quais apontam que um aluno intrinsecamente motivado preza pela qualidade e melhores resultados de aprendizagem, por isso faz uso de estratégias de aprendizagem como forma de maximizar o desempenho escolar (Cordova \& Lepper, 1996; Ryan \& Deci, 2000; Lepper, Corpus, \& Lyegar, 2005; Steinmayr \& Spinath, 2009). 
Na mesma direção, o fator "Ausência de Estratégias" está positivamente correlacionado com Motivação Extrínseca, do tipo "apenas por obrigação", ou seja, quanto maior esse tipo de motivação, maior a ausência de estratégias de aprendizagem. Assim, estudar por obrigação parece "desmotivar" o aluno a estabelecer estratégias de aprendizagem.

O fator "Estratégias metacognitivas" apresentou correlação negativa e significativa (ao nível significância de 1\%) com a Motivação Extrínseca - por punição. Esses resultados mostram que os alunos que estudam para evitar punições são avessos ao uso de estratégias de aprendizagem, enquanto aqueles que se dedicam ao estudo das melhores estratégias de aprendizagem não são motivados por punições.

Por outro lado, foram verificadas correlações positivas e significativas entre o fator "Estratégias Metacognitivas" e os dois tipos de motivação intrínseca. Esse resultado reforça a análise feita anteriormente, qual seja, os alunos intrinsecamente motivados se dedicam ao estudo de estratégias para regular e aprimorar o processo de aprendizagem.

Da forma surpreendente, a "Motivação extrínseca - apenas por obrigação" também se mostrou positivamente correlacionada com o fator "Estratégias Metacognitivas", evidenciando que, entre os alunos de Ciências Contábeis, o senso de "cumprir obrigações" está correlacionado à regulação da aprendizagem por meio do estudo de estratégias que visem melhorar aprendizado. Talvez o caráter pragmático da profissão possa explicar esse comportamento.

Coerente com os resultados anteriores, pode-se verificar correlação positiva e significativa entre o fator "Estratégias cognitivas" e os dois fatores relativos à motivação intrínseca, isto é, quanto mais intrinsecamente motivados, mais os alunos regulam o processo de aprendizagem por meio estratégias, mesmo que seja inconscientemente.

Conforme as definições de Garner e Alexander (1989) e Dembo (1994), estratégias cognitivas são comportamentos e pensamentos que influenciam o processo de aprendizagem, de forma que a informação possa ser recuperada mais eficientemente da memória, sempre que necessário. As estratégias de ensaio, elaboração e organização do conhecimento são exemplos de estratégias cognitivas. O ensaio consiste na repetição e no repasse da informação por parte do estudante, e a elaboração possibilita que o aprendiz estabeleça relações entre um conteúdo novo e os conhecimentos que ele já detém. Já a organização é a atividade pela qual o aluno identifica as ideias principais do novo conteúdo e estabelece ligações entre suas diversas partes. Essa preocupação em ter uma boa aprendizagem pode ser identificada quando o aluno lê um texto e procura escrever com suas palavras o que entendeu da leitura, para estudar depois ou, simplesmente, quando ele procura ler outros textos sobre o assunto que o professor ensinou em sala de aula.

Também houve correlação positiva e significativa (ao nível significância de 1\%) entre o fator "Estratégias cognitivas" e a Motivação extrínseca - por punição, ou seja, quando sujeitos a algum tipo de punição, os alunos investigados buscam alternativas para o aprendizado do conteúdo.

\section{CONCLUSÃO DA PESQUISA}

Considerando o objetivo proposto para este estudo, que é o de verificar a relação entre o uso das estratégias de aprendizagem e os tipos de motivação discente de alunos de Ciências Contábeis, verificou-se que a motivação intrínseca está positivamente correlacionada ao uso de estratégias de aprendizagem pelos discentes em seu processo de estudo. Por outro lado, alunos que estudam motivados por 
obrigações, recompensas e punições, em sua maioria, não estão motivados intrinsecamente; quando estão, o tipo de motivação é extrínseca.

O desempenho escolar pode ser melhorado à medida que os alunos colocam em prática estratégias que facilitam seu processo cognitivo. Em contrapartida, a melhora no desempenho pode aumentar a motivação intrínseca do aluno, despertando nele o prazer e a vontade de estudar e esforçar-se para melhorar seus resultados.

No entanto, saber como e quando colocar em prática as estratégias de aprendizagem não deve ser um dever apenas dos discentes, mas também dos docentes. Os professores devem saber que estratégias ensinadas podem possibilitar a tomada de consciência do aluno, levando-o a compreender que existem tarefas cognitivas que podem ser automatizadas, mas também há atividades que requerem planejamento prévio, regulação e avaliação do processo (Boruchovitch \& Santos, 2006; Oliveira, Boruchovitch, \& Santos, 2010).

De acordo com Ryan e Deci (2000), toda motivação depende também de fatores ambientais. Nesse sentido, o professor, como agente destinado a conduzir o aluno a construir seu conhecimento, necessita promover iniciativas capazes de motivar o discente a aprender. Existem muitas ações que podem ser promovidas pelos docentes para motivar o aluno, dentre elas, mostrar que ele é capaz de construir seu próprio conhecimento, por meio de um processo de aprendizagem autônomo, eficiente e direcionado. Além disso, o docente deve evidenciar a importância dos estudos para atingimento de suas metas pessoais, mostrar valor e significado pessoal das aprendizagens, dar feedback ao desempenho, de forma que alimente o senso de competência. Sendo um fomentador da motivação para aprender, o professor será capaz de incentivar os alunos a adotarem o uso das estratégias de aprendizagem. Também, melhor conhecimento e prática relativos a aprender a aprender assegurariam escores mais elevados nas subescalas de estratégias cognitivas e metacognitivas (Dembo, 1994; Boruchovitch, 1999; Boruchovitch \& Santos, 2006; Leite \& Darsie, 2011; Weinstein, Acee, \& Jung, 2011).

Esta pesquisa contribui com a literatura, pois revela como os alunos controlam ou gerenciam seus processos de aprendizagem, evidenciando qual o tipo de motivação - intrínseca ou extrínseca - que predomina entre eles e qual a relação entre o tipo de motivação e o uso de estratégias de aprendizagem. Ademais, este estudo mostra a importância da participação do docente no processo de aprendizagem do aluno, pois estudos anteriores mostram que os alunos podem aprender estratégias de aprendizagem e que a motivação está relacionada com o desempenho acadêmico na área de negócios (Miranda, et al. 2013).

A principal limitação desta pesquisa se refere à amostra restrita a alunos do curso de Ciências Contábeis de uma instituição, visto que, por não se tratar de uma amostra probabilística, não possibilita a generalização dos resultados. Para trabalhos futuros, sugere-se que se realizem pesquisas nas quais se amplie o número de instituições, considerando, também, outros cursos da área de negócios, como Administração e Economia, e até mesmo cursos de programas de pós-graduação stricto sensu, para comparação com os resultados encontrados neste estudo. Sugere-se também a realização de pesquisas para confirmar e compreender as causas que levam os alunos de Ciências Contábeis a estabelecerem estratégias metacognitivas diante de motivações extrínsecas por obrigação. 


\section{REFERÊNCIAS}

Amabile, T. M., Hill, K. G., Hennessey, B. A., \&Tighe, E. M. (1994). The work preference inventory: Assessing intrinsic and extrinsic motivation orientation. Journal of Personality and Social Psychology, 6(5), 950-967.

Araújo, T.S. Lima, F.D. C., Oliveira, A.C.L., \& Miranda, G.J. (2015) Problemas Percebidos no Exercício da Docência em Contabilidade. Revista de Contabilidade e Finanças - USP, São Paulo, v. 26, n. 67, p. 93105, jan. /fev. /mar./abr.

Boruchovitch, E., \& Santos, A. A. A. (2004). Escala de avaliação de estratégias de aprendizagem para crianças do ensino fundamental. Manuscrito não publicado. Universidade São Francisco, Bragança Paulista-SP.

Boruchovitch, E. (2006). Estratégias de aprendizagem: uma análise à luz das variáveis demográficas e motivacionais. Tese de Livre-docência não publicada. Universidade Estadual de Campinas, Faculdade de Educação. Campinas, SP.

Boruchovitch, E., \& Santos, A. A. A. (2006). Estratégias de aprendizagem: conceituação e avaliação. Em: A. P. P. Noronha, \& F. F. Sisto, (Orgs.). Facetas do fazer em avaliação psicológica. (pp. 10-20). São Paulo:Vetor.

Boruchovitch, E. (2008, janeiro/abril). A motivação para aprender de estudantes em curso de formação de professores. Educação, Porto Alegre, 31 (1), 30-38.

BRASIL. Ministério da Educação. Instituto Nacional de Estudos e Pesquisas Educacionais Anísio Teixeira - INEP. Censo da Educação Superior 2012: resumo técnico. Brasília: Instituto Nacional de Estudos e Pesquisas Educacionais Anísio Teixeira, 2014. Disponível em: http://download.inep.gov.br/download/ superior/censo/2012/resumo_tecnico_censo_educacao_superior_2012.pdf. Acesso em: 20 mar. 2015.

BRASIL. Ministério da Educação. Instituto Nacional de Estudos e Pesquisas Educacionais Anísio Teixeira - INEP. Censo da Educação Superior 2013: apresentação coletiva. Brasília: Instituto Nacional de Estudos e Pesquisas Educacionais Anísio Teixeira, 2014. Disponível em: http://download.inep.gov.br/ educacao_superior/censo_superior/apresentacao/2014/coletiva_censo_superior_2013.pdf. Acesso em: 20 mar. 2015.

Bzuneck, J. A. (2009). A motivação do aluno: aspectos introdutórios. Em: E. Boruchovitch, \& J. A. Bzuneck (Orgs.), A motivação do aluno: contribuições da psicologia contemporânea (pp. 9-36). Petrópolis:Vozes. (Original publicado em 2001).

Bzuneck, J. A., \& Guimarães, S. E. R. (2010). A promoção da autonomia como estratégia motivacional na escola. Em: E. Boruchovitch, J. A. Bzuneck, \& S. E. R. Guirmarães (Orgs.), Motivação para aprender: aplicações no contexto educativo. (pp. 41-70). Petrópolis-RJ: Vozes.

Cardoso, L. R., \& Bzuneck, J. A. (2004). Motivação no ensino superior: metas de realização e estratégias de aprendizagem. Psicologia Escolar e Educacional, 8(2), 145-155.

Cordova, D. I., \& Lepper, M. R. (1996). Intrinsic Motivation and the process of learning: beneficial effects of contextualization, personalization, and choice. Journal of Educational Psychology, 88(4), 715-730.

Csikszentmihalyi, M., \& Nakamura, J. (1989). The dynamics of intrinsic motivation: A study of adolescents. In C. Ames \& R. Ames (Eds.), Research on motivation in education: Vol. 3. Goals and cognitions (pp. 249277). New York: Academic Press.

Da Silva A. L., \& De Sa, L. (1997). Saber estudar e estudar para saber. Coleção Ciências da Educação. Porto: Porto Editora.

Dansereau, D. (1985). Learning strategy research. Em: J. W. Segal, S. F. Chipman, \& R. Glaser (Orgs.), Thinking and Learning Skills (pp. 209-239). Hillsdale, NJ: Erlbaum. 
Deci, E. L., \& Ryan, R. M. (1985). Intrinsic motivation and self-determination in human behavior. New York: Plenum.

Deci, E. L., Vallerand, R. J., Pelletier, L. G., \& Ryan, R. M. (1991). Motivation in education: The self-determination perspective. Educational Psychologist, 26(3/4), 325-346.

Dembo, M. H. (1994). Applying educational psychology. New York: Longman Publishing Group.

Fávero, L. P., Belfiore, P. P., Silva, F. L. da., \& Chan, B. L. (2009). Análise de dados: modelagem multivariada para tomada de decisões. Rio de Janeiro: Elsevier

Fortier, M. S., Vallerand, R. J., \& Guay, F. (1995). Academic motivational and school performance: Toward a structural model. Contemporary Educational Psychology, 20(3), 257-274.

Garner, R., \& Alexander, P. A. (1989). Metacognition: Answered and unanswered questions. Educational Psychologist, 24(2), 143-158.

Garner, R., Hare, V. C., Alexander, P., Haynes, J., \& Winograd, P. (1984). Inducing use of a text lookback strategy among unsucessful readers. American Educational Research Journal, 21, 789-798.

Gonçalves, C. A.; \& Meirelles, A. M. (2004). Projetos e relatórios de pesquisa em administração. São Paulo: Atlas.

Graham, S., \& Weiner, B. (1996). Theories and principles of motivation. Em: D. C. Berliner, \& R. C. Calfee (Orgs.), Handbook of Educational Psychology, (pp. 63-84). New York: Macmillan.

Guimarães, S. E. R. (2009). Motivação intrínseca, extrínseca e o uso de recompensas externas em sala de aula. Em: E. Boruchovitch, \& J. A. Bzuneck (Orgs.), A motivação do aluno: contribuições da psicologia contemporânea (pp. 37-57). Petrópolis: Vozes.

Guimarães, S. E. R., Bzuneck, J. A., \& Boruchovitch, E. (2010). Instrumentos brasileiros de avaliação da motivação no contexto escolar: contribuições para pesquisa, diagnóstico e intervenção. Em: E. Boruchovitch, J. A. Bzuneck, \& S. E. R.

Guimarães (Orgs.), Motivação para aprender: aplicações no contexto educativo (pp. 71-96). Petrópolis: Vozes.

Hair Jr, J. F., Black, W. C., Babin, B. J., Anderson, R. E., \&Tatham, R. L. (2005). Análise multivariada de dados. Porto Alegre: Bookman.

Harackiewicks, J. M., \& Elliot, A. J. (1993). Achievement goals and intrinsic motivation. Journal of Personality and Social Psychology, 65(5), 904-915.

Harter, S. (1981). A new self-report scale of intrinsic versus extrinsic orientation in the classroom: Motivational and informational components. Developmental Psychology, 17(3), 300-312.

Hattie, J. Biggs, J., \& Purdie, N. (1996). Effects of learning skills interventions on students: A meta analysis. Review of Educational Research, 66(2), 99-136.

Instituto Nacional de Estudos e Pesquisas Educacionais Anísio Teixeira. INEP. (2012). Indicadores de qualidade da educação superior 2012. Nota metodológica. Brasília: INEP, 2013. Recuperado em 14 dezembro, 2013, de http://download.inep.gov.br/educacao_superior/ENADE/notas_tecnicas/2012/ nota_metodologica_indicadores_2012.pdf

Leal E.A., Miranda, G. J., \& Carmo, C. R. S. (2013). Teoria da Autodeterminação: uma Análise da Motivação dos Estudantes do Curso de Ciências Contábeis, Revista de contabilidade e Finanças, USP, v. 24, n.62, p.162-173. 
Leite, E. A. P.k., \& Darsie, M. M. P. (2011). Implicações da metacognição no processo de aprendizagem de matemática. Revista Eletrônica de Educação, 5(2), 179-191.

Lepper, M. R., Corpus, J. H., \& lyengar, S. (2005). Intrinsic and extrinsic motivation in the classroom: Age differences and academic correlates. Journal of Educational Psychology, 97(2), 184-196.

Lins, M. R. C., Araujo, M. R., \& Minervino, C. A. S. M. (2011). Estratégias de aprendizagem empregadas por estudantes do Ensino Fundamental. Psicologia Escolar e Educacional, 15(1), 63-70.

Malhotra, K. N. (2001). Pesquisa de Marketing. Porto Alegre: Bookman.

Mamede, S. P. N., Marques, A. V. C., Rogers, P., \& Miranda, G. J. (2015). Psychological Determinants of Academic Achievement in Accounting: Evidence from Brazil. Brazilian Business Review, 13(2), 50-71.

Mandelink, G., \& Harackiewicz, J. (1984). Proximal versus distal goal setting and intrinsic motivation. Journal of Personality and Social Psychology, 47(4), 918-928.

Martinelli, S. C., \& Genari, C. H. M. (2009). Relações entre desempenho escolar e orientações motivacionais. Estudos de Psicologia, 14(1), 13-21.

Mitchell Jr., J.V. (1992). Interrelationships and predictive efficacy for indices of intrinsic and extrinsic, and self-assessed motivation for learning. Journal of Research and Development in Education, 25(3), 149-155.

Neves, E. R. C., \& Boruchovitch, E. (2007). Escala de avaliação da motivação para aprender de alunos do Ensino Fundamental (EMA). Psicologia: Reflexão e Crítica, 20(3), 406-413.

Nisbet, J., \& Schucksmith, J. (1986). Learning strategies. London: Routledge \& Kegan Paul.

Oliveira, K. L., Boruchovitch, E., \& Santos, A. A. A. (2010). Escala de avaliação de estratégias de aprendizagem para o Ensino Fundamental - EAVAP - EF. São Paulo: Casa do Psicólogo.

Paiva, M. L. P., \& Boruchovitch, E. (2010). Orientações motivacionais, crenças educacionais e desempenho escolar de estudantes do Ensino Fundamental. Psicologia em Estudo, 15(2) 235-244.

Perassinoto, Maria Gislaine M., Boruchovitch, E., \& Bzunek, J. A. (2013). Estratégias De Aprendizagem e motivação para aprender de alunos do Ensino Fundamental.

Pozo, J. J. (1996). Estratégias de Aprendizagem. Em: C. Coll., J. Palácios, \& A. Marchesi, (Orgs), Desenvolvimento psicológico e educação: psicologia da educação (pp. 176-197). Porto Alegre: Artes Médicas.

Pressley, M., \& Levin, J. R. (1983). Cognitive strategy research: Psychological Foundations. New York: Springer-Verlag.

Ryan, R. M., \& Deci, E. L. (2000). Intrinsic and extrinsic motivations: classic definitions and new directions. Contemporary Educational Psychology, 25, 54-67.

Shil, S. S. (2005). The role of achievement goals in children's learning in Taiwan. The Journal of Educational Research, 1(5), 310-319.

Siqueira, L. G. G., \& Wechsler, S. M. (2006). Motivação para a aprendizagem escolar: possibilidade de medida. Revista Avaliação Psicológica, 5(1), 21-31.

Steinmayr, R., \& Spinath, B. (2009). The importance of motivation as a predictor of school achievement. Learning and Individual Differences, 19(1), 80-90.

Triviños, A. N. S.(2007). Introdução à Pesquisa em Ciências Sociais: a pesquisa qualitativa em educação. 1 ed. 15. Reimpr, São Paulo, Atlas. 
Weinstein, C. E., \& Mayer, R. E. (1985). The teaching of learning strategies. Em M. Wittrock (Org.), Handbook of research on teaching (pp.315-327). New York: Macmillan.

Weinstein, C. E., \& Mayer, R. E. (1986). The Teaching of Learning Strategies. Em: M. C. Wittrock (Org.), Handbook of Research on Teaching (pp. 315-327). New York: McMillan Publ. Co.

Weinstein, C. E., \& Acee, T. W, Jung, J. (2011). Self regulation and learning strategies. New Directions for Teaching and Learning, 16, 45-53.

Zimmerman, B. J., \& Martinez-Pons, M. (1986). Development of a structured interview for assessing student use of self-regulated learning strategies. American Educational Research Journal, 23, 614-628. 